\title{
How Does Patient Socioeconomic Position Affect Breast Cancer Surgical Treatment and Mortality?: A Rapid Review
}

\author{
Danielle Schubbe $\mathbb{D}^{\prime}$ \\ Renata W Yen (iD) \\ Marie-Anne Durand (iD) $1-3$ \\ 'The Dartmouth Institute for Health \\ Policy and Clinical Practice, Dartmouth \\ College, Lebanon, NH, USA; ${ }^{2}$ UMR I295, \\ CERPOP, Université de Toulouse, \\ INSERM, Université Toulouse II Paul \\ Sabatier, Toulouse, France; ${ }^{3}$ Unisanté, \\ Centre universitaire de médecine \\ générale et santé publique, Lausanne, \\ $\mathrm{CH}-10 \mathrm{II}$, Switzerland
}

Background: Breast cancer is the second leading cause of death in women across the world. Despite significant improvements in overall breast cancer survival, disparities still exist. Research shows that socioeconomic position (SEP) plays a strong role in disparities in breast cancer care. Lower SEP can be a predictor of poorer breast cancer health outcomes and treatment received. No recent review has focused on SEP and breast cancer surgery outcomes. We conducted a rapid review assessing how patient SEP affects breast cancer surgical outcomes.

Methods: We developed and ran the search strategy in Ovid MEDLINE in January 2021. We assessed study eligibility using an adapted version of PICOS criteria. We included observational studies that assessed the relationship between SEP and breast cancer surgery treatment, including outcomes like surgery choice, survival, and wait time to surgery. We independently reviewed each article and independently extracted data using a pre-designed form. One reviewer narratively synthesized the data extracted from the included articles.

Results: We found twelve articles that met inclusion criteria. Eight out of 12 articles showed a difference in breast cancer surgery outcomes based on at least one measure of SEP. Six out of eight articles that collected surgery choice data found that women with lower SEP had lower rates of breast conserving surgery. One out of three articles that collected survival data found that higher SEP had a positive effect on survival. Additionally, one article that collected wait time to surgery data found a significant correlation between lower SEP and longer delays to surgical treatment.

Conclusion: In conclusion, our rapid review of SEP and breast cancer surgery outcomes found that there is a relationship between SEP and breast cancer surgery choice. This rapid review did not find enough evidence to see a relationship with overall survival and wait time to surgery.

Keywords: breast cancer, socioeconomic position, disparity, review

\section{Plain Language Summary}

Lower socioeconomic position (SEP) is a predictor of poor outcomes and treatment of women with breast cancer. Lower SEP can include lower income, little education, unemployment, and poor household conditions. We conducted a rapid review on the relationship between SEP and breast cancer surgery outcomes, like surgery choice, survival, and wait time to surgery.

We found twelve articles that met our inclusion criteria. Eight of twelve articles found a relationship between SEP and breast cancer surgery outcomes. Six articles found that lower SEP resulted in lower rates of breast-conserving surgery. One article found that higher SEP resulted in better survival. One article found that women with lower SEP had longer delays to surgical treatment. 
Our rapid review of SEP and breast cancer surgery outcomes found that there is a relationship between SEP and breast cancer surgery choice. We did not find enough evidence to see a relationship with survival and wait time to surgery. We suggest a more in-depth systematic review and potential meta-analysis on the relationship between SEP and breast cancer surgery outcomes.

\section{Introduction}

Breast cancer is the most commonly diagnosed malignancy and second leading cause of death in women across the world. ${ }^{1}$ Advances in screening methods have meant that breast cancer is increasingly diagnosed in its early stages, resulting in higher survival. Diagnosed early, treatment is successful in about $80 \%$ of patients with breast cancer. ${ }^{2}$ Surgical treatment of breast cancer has progressed. It is most often locoregional, with two options commonly available: breast conserving surgery (BCS) followed by several weeks of radiotherapy or mastectomy (typically not followed by radiotherapy). ${ }^{3-6}$ Although BCS is the recommended treatment for earlystage breast cancer (stages I to IIIA), research to date has primarily shown equivalent survival for both mastectomy and $\mathrm{BCS}^{4}$ Both options are offered routinely yet have distinct harms and benefits. ${ }^{7}$

Despite significant improvements in overall breast cancer survival, disparities associated with breast cancer have been reported. ${ }^{8,9}$ In other words, poor outcomes and death from breast cancer care are not distributed equally in the population. Inequities have increased with advances in screening and treatments. The Institute of Medicine defines a health service disparity as "a difference in treatment or access not justified by differences in health status or preferences of the population groups". ${ }^{10}$ There is no evidence that women diagnosed with breast cancer have distinct values and preferences that explain different outcomes and mortality rates. Differences in treatment received and patient-centered health outcomes are disparities that seem to predominantly affect certain groups of women with breast cancer. ${ }^{8}$

Disparities in treatment and outcomes are not specific to breast cancer care but a growing challenge across cancer types. ${ }^{11}$ Outcomes are not equal regarding the type and quality of cancer care received as well as the quality and length of survival. These disparities are estimated to result in approximately 700,000 life-years lost every year. ${ }^{11}$ Added to this are the ethical and societal implications of widening gaps in a modern society that should provide equal access to care for all. Although race and ethnicity have played an undeniable role in breast cancer inequities, evidence suggests that socioeconomic position (SEP) plays an even stronger role. ${ }^{12}$ SEP refers to the social and economic factors that influence what positions individuals or groups hold within the structure of a society. ${ }^{13}$ Key indicators of SEP include education, occupation, income, and household condition. ${ }^{13}$ Research suggests that differences in treatment received and patient-centered health outcomes are disparities that predominantly affect women of lower SEP with breast cancer, irrespective of race or ethnicity. ${ }^{14,15}$ For breast cancer, lower SEP is considered a stronger predictor of poor outcomes and treatment received than race or ethnicity. ${ }^{12}$

To our knowledge, no recent review has explicitly focused on SEP and breast cancer surgery outcomes. This is particularly relevant as breast cancer surgical treatment keeps evolving. Our aim was thus to conduct a rapid review assessing how patient SEP affects breast cancer surgical outcomes.

\section{Methods}

\section{Eligibility Criteria}

We assessed study eligibility by adapting the "Population Intervention Control Outcomes and Study design" (PICOS) criteria, excluding "Intervention", as we are only including observational studies. ${ }^{16}$ We included observational studies that assessed the relationship between SEP and breast cancer surgery treatment. Please see Table 1 for inclusion and exclusion criteria.

According to Galobardes et al article on SEP,

The choice of SEP measure(s) should be ideally informed by consideration of the specific research question and the proposed mechanisms linking SEP to the outcome. ${ }^{13}$

Therefore, for our rapid review, we will consider any factors of SEP: education, government assistance housing or homelessness, income, or employment. In determining the inclusion of articles, we used the author's definition of lower or higher SEP, as long as it included one of the factors of determining SEP.

We excluded randomized controlled trials (RCT) because the primary analyses of an RCT do not typically explore the causal relationships between SEP and outcomes. Secondary data analyses in RCTs might look at the causal relationship between SEP and outcomes, but the relationship may be clouded by the intervention's effect. 
Table I Inclusion and Exclusion Criteria

\begin{tabular}{|l|l|l|}
\hline Parameter & Inclusion Criteria & Exclusion Criteria \\
\hline Population & $\begin{array}{l}\text { Adult female patients (I8 years and older) Confirmed } \\
\text { breast cancer diagnosis }\end{array}$ & $\begin{array}{l}\text { Adolescents/children } \\
\text { DCIS }\end{array}$ \\
\hline Comparator & $\begin{array}{l}\text { Includes at least one operational definition, measure, or } \\
\text { indicator of socioeconomic position (SEP) }\end{array}$ & $\begin{array}{l}\text { Not directly reported patient demographics: } \\
\text { - Health insurance status as proxy for SEP } \\
\text { - Ecological data used as proxy for SEP - zip code, Census data } \\
\text { for zip code } \\
\text { SEP is only adjusted or controlled for in analysis }\end{array}$ \\
\hline Outcomes & $\begin{array}{l}\text { Direct surgical outcome(s): surgery choice, delays to } \\
\text { treatment, and/or survival }\end{array}$ & $\begin{array}{l}\text { Other surgery: breast reconstruction and prophylactic mastectomy } \\
\text { (and contralateral prophylactic mastectomy) }\end{array}$ \\
\hline $\begin{array}{l}\text { Study } \\
\text { Design }\end{array}$ & $\begin{array}{l}\text { Only observational studies - cohort, cross-sectional, case } \\
\text { series/studies }\end{array}$ & $\begin{array}{l}\text { Randomized controlled trials } \\
\text { Publications in a language other than English or French } \\
\text { No quantitative results }\end{array}$ \\
\hline
\end{tabular}

We also excluded studies that do not provide quantitative results because we would not be able to see a causal relationship.

Additionally, we excluded health insurance status (highly variable across countries) and ecological data as proxies for SEP. We chose to only include directly reported patient demographics to make a more accurate comparison between SEP and direct surgical outcomes.

\section{Searches and Study Selection}

We collaboratively developed the search strategy and ran it in Ovid MEDLINE in January 2021 (see Appendix 1). Additionally, one independent reviewer (DS) manually conducted (1) a reference and "cited by" search of included primary articles and relevant reviews and (2) a search of the first 100 hits in Google Scholar to search across cross-disciplinary articles.

Two independent reviewers per citation (DS and RWY/ MAD) screened the title and abstract of all database search articles for eligibility. Two independent reviewers per citation (DS, RWY, MAD) screened the full-text articles for inclusion for data extraction. Any discrepancies were resolved as a group. We screened articles using Rayyan, a web application designed for screening systematic review records. ${ }^{17}$

\section{Data Extraction and Synthesis}

Three independent extractors (DS, RWY, MAD) extracted data using a pre-designed form. We extracted data about author name(s), publication year, country, setting, how SEP is defined in the article, outcome(s) and its statement of result(s), and follow-up information (if reported). We did not conduct a quality assessment of the selected articles as this was a rapid review. One reviewer (DS) narratively synthesized the descriptives of the articles and data collected by outcome.

\section{Results}

We screened the titles and abstracts of 806 unique articles, assessed the full text of 70 articles, and found twelve articles that met all inclusion criteria for qualitative synthesis. ${ }^{18-29}$ The selected articles ranged in publication date from 1997 to 2020 with data collected from 1970 to 2017. Three articles reported on data collected in the United States, three in China, and one each in Canada, United Kingdom, Denmark, Italy, Sweden, and Pakistan. Ten articles reported data collected from a database, whereas two articles reported data that was being collected as part of a broader research study. The majority of articles $(n=8)$ collected surgery choice as the main outcome, three collected overall survival data, and one measured delays to treatment. Additionally, the majority of articles determined SEP using income and educational attainment, most often self-reported and less often directly pulled from databases. Eight out of 12 articles showed some difference in breast cancer surgery outcomes based on at least one measure of SEP. ${ }^{18,20,21,24,26-29}$ Please see Table 2 for a brief description of the included articles.

\section{Breast Cancer Surgery Choice}

A total of eight articles out of 12 assessed the relationship between SEP and breast cancer surgery choice. In articles that collected the education levels of the patients, five out 
Table 2 Brief Characteristics of Included Articles

\begin{tabular}{|c|c|c|c|c|}
\hline Article Authors & Year & Country & Measure of SEP & $\begin{array}{l}\text { Outcome } \\
\text { Measured }\end{array}$ \\
\hline Aziz et $\mathrm{al}^{19}$ & 2010 & Pakistan & $\begin{array}{l}\text { Patient-reported income. Low: Up to } \$ 1 \text { I/day; } \\
\text { Middle: Between } \$ 1 \text { I and } \$ 25 / \text { day; High: } \\
\text { Greater than } \$ 25 / \text { day. }\end{array}$ & Survival \\
\hline Chen et $\mathrm{al}^{20}$ & 2019 & China & $\begin{array}{l}\text { Self-reported income, self-reported level of } \\
\text { education }\end{array}$ & Surgery choice \\
\hline Dalton et $\mathrm{al}^{2 \mathrm{l}}$ & 2007 & Denmark & $\begin{array}{l}\text { Individual level database. Level of education, } \\
\text { employment status, and income. }\end{array}$ & Survival \\
\hline Frisell et $\mathrm{al}^{22}$ & 2020 & Sweden & $\begin{array}{l}\text { Self-reported education level, occupation, } \\
\text { disposable income. }\end{array}$ & Surgery choice \\
\hline Haybittle et $\mathrm{al}^{23}$ & 1997 & United Kingdom & Self-reported occupation. & Survival \\
\hline Lautner et $\mathrm{al}^{24}$ & 2015 & $\begin{array}{l}\text { United States of } \\
\text { America }\end{array}$ & $\begin{array}{l}\text { Self-reported income, self-reported education } \\
\text { level. }\end{array}$ & Surgery choice \\
\hline $\mathrm{Li}$ et $\mathrm{al}^{25}$ & 2019 & Canada & $\begin{array}{l}\text { Self-reported income, self-reported education } \\
\text { level. }\end{array}$ & Surgery choice \\
\hline Liu et $\mathrm{al}^{26}$ & 2012 & China & $\begin{array}{l}\text { Self-reported family income, self-reported level } \\
\text { of education. }\end{array}$ & Surgery choice \\
\hline Riba et $\mathrm{al}^{27}$ & 2019 & $\begin{array}{l}\text { United States of } \\
\text { America }\end{array}$ & Self-reported income. & Surgery choice \\
\hline $\begin{array}{l}\text { Porzio G. }{ }^{18} \text { The Italian Group for } \\
\text { the Evaluation of Outcomes in } \\
\text { Oncology (IGEO) }\end{array}$ & 2003 & Italy & $\begin{array}{l}\text { Self-reported level of education, self-reported } \\
\text { occupation. }\end{array}$ & Surgery choice \\
\hline Wright et $\mathrm{al}^{28}$ & 2010 & $\begin{array}{l}\text { United States of } \\
\text { America }\end{array}$ & Self-reported SES quintile. & Wait time to surgery \\
\hline Zhang et $\mathrm{al}^{29}$ & 2012 & China & $\begin{array}{l}\text { Self-reported income, self-reported level of } \\
\text { education. }\end{array}$ & Surgery choice \\
\hline
\end{tabular}

of seven showed that rates of BCS were lower (compared to mastectomy) among patients with lower education. $^{18,20,24,26,29}$ One article noted that the patient group that made less than $\$ 30,000$ per year had the lowest rates of $\mathrm{BCS}^{24}$ Two out of seven articles showed no relationship between education level and rates of BCS. $^{22,25}$ In articles that collected patients' incomes, most often self-reported, five out of seven showed that rates of BCS were lower (compared to mastectomy) among patients with lower income. ${ }^{20,24,26,27,29}$ Two articles showed no relationship between income level and rates of $\mathrm{BCS}^{22,25}$

\section{Survival}

Three articles assessed the relationship between SEP and overall survival. ${ }^{19,21,23}$ Only one out of three articles that reported data collected on overall survival data showed that higher SEP had a positive effect on overall survival, with higher education and higher income as factors for a lower hazard ratio. ${ }^{21}$ Two articles found no statistically significant effect of SEP on overall survival. ${ }^{19,23}$

\section{Wait Time to Surgery}

Only one article assessed the relationship between SEP and wait time to surgery. This article found that women with lower SEP had longer delays to surgical treatment, especially for patients who had already waited 90 days or longer. ${ }^{28}$

\section{Discussion}

Our rapid review included 12 articles across eight countries that mostly reported data from database registries. 
Based on our rapid review, we found that approximately two-thirds of articles found a relationship between SEP and breast cancer surgery outcomes. Our results show that, generally, there is a relationship between lower SEP and lower rates of BCS. We found only one article each that stated that lower SEP lowered survival and increased wait time to surgery for patients with breast cancer. Based on this rapid review, there is not enough evidence to determine whether there is a relationship between SEP and breast cancer survival or wait time to surgery.

Similarly, in a separate review of the effects of SEP along the breast cancer continuum in Australia, they also found that the effects of SEP on survival were inconclusive. ${ }^{30} \mathrm{~A}$ review focusing on surgical decision-making confirmed our finding that SEP affects breast cancer surgical treatment (relationship between lower SEP and lower rates of BCS). ${ }^{31}$ The review explains that the disparity is likely due to differing patientphysician communication patterns based on SEP, in which higher-income women are perceived to be more comfortable asking questions about their surgical treatment options. ${ }^{31} \mathrm{An}$ article included in this review that examined the differences in breast cancer surgery choices among Swedish women suggested taking into account these disparities in pre-operative counselling. ${ }^{22}$ Research shows that the use of conversation aids can increase patients' participation in decision-making across socioeconomic strata, particularly in circumstances where more than one reasonable treatment option exists. ${ }^{32,33}$

There were both strengths and limitations to this rapid review. A notable disadvantage of this rapid review is that many articles were excluded due to using an ecological SES variable to measure SEP. We decided to not include those articles because there was no exactness of a particular patient's SEP. Additionally, excluding health insurance status may be a limitation to this review due to international differences in insurance type and coverage. This may particularly affect women with lower SEP in other countries where BCS and mastectomy are not approximately equal in cost. The main strength of this rapid review is that the selection of articles was based on being able to look directly at the effect of SEP on a breast cancer patient's surgical outcomes, whether it be surgery choice, survival, or wait time to surgery. Another strength of this rapid review was using SEP, which has more clearly defined determinants, rather than socioeconomic status broadly. Using SEP provides a clearer guideline of what demographic variables to consider and can be assessed across different countries, rather than socioeconomic status, which is mainly used as a term in the US.
We feel this rapid review helps support the necessity of conducting a larger, more in-depth systematic review and potential meta-analysis of SEP and breast cancer surgery outcomes. For a larger review, we suggest including ecological factors, particularly zip code, as a determinant of SEP, as it has been found to be an accurate measure of area-based SEP. ${ }^{34}$ We also recommend using SEP in place of socioeconomic status, as the former provides more flexibility in use across countries and clearly determined demographic variables to consider.

\section{Conclusion}

In conclusion, our rapid review of SEP and breast cancer surgery outcomes found that there is a relationship between SEP and breast cancer surgery choice, but there is not enough evidence to see a relationship with survival and wait time to surgery. Our rapid review provides sufficient rationale to conduct a systematic review and metaanalysis of current literature. Our rapid review was also novel in our approach of focusing on SEP.

\section{Data Sharing Statement}

If interested and when requested, we are able to provide our data extraction sheet if the corresponding author is contacted.

\section{Ethics Approval and Informed Consent}

As this rapid review was conducted without any direct patient or participant contact, we did not need ethics approval or informed consent.

\section{Acknowledgments}

Thank you to Heather Blunt from Dartmouth Biomedical Libraries, who helped us narrow down our search strategy. We would also like to thank Dr. Cyrille Delpierre, who read the manuscript and provided valuable feedback.

\section{Author Contributions}

All authors contributed to data analysis, drafting or revising the article, gave final approval of the version to be published, agreed to the submitted journal, and agreed to be accountable for all aspects of the work.

\section{Funding}

This research was conducted without funding or financial support. 


\section{Disclosure}

Marie-Anne Durand has contributed to the development of Option Grid patient decision aids. EBSCO Information Services sells subscription access to Option Grid patient decision aids. She receives consulting income from EBSCO Health, and royalties. The authors report no other conflicts of interest in this work.

\section{References}

1. Donepudi MS, Kondapalli K, Amos SJ, Venkanteshan P. Breast cancer statistics and markers. J Cancer Res Ther. 2014;10 (3):506-511. doi:10.4103/0973-1482.137927

2. Harbeck N, Penault-Llorca F, Cortes J, et al. Breast cancer. Nat Rev Dis Primers. 2019;5(1):66. doi:10.1038/s41572-019-0111-2

3. Fisher B, Anderson S, Bryant J, et al. Twenty-year follow-up of a randomized trial comparing total mastectomy, lumpectomy, and lumpectomy plus irradiation for the treatment of invasive breast cancer. $N$ Engl J Med. 2002;347(16):1233-1241. doi:10.1056/ NEJMoa022152

4. Jatoi I, Proschan MA. Randomized trials of breast-conserving therapy versus mastectomy for primary breast cancer: a pooled analysis of updated results. Am J Clin Oncol. 2005;28(3):289-294. doi:10.1097/ 01.coc.0000156922.58631.d7

5. Morris AD, Morris RD, Wilson JF, et al. Breast-conserving therapy vs mastectomy in early-stage breast cancer: a meta-analysis of 10-year survival. Cancer J Sci Am. 1997;3(1):6-12.

6. Poggi MM, Danforth DN, Sciuto LC, et al. Eighteen-year results in the treatment of early breast carcinoma with mastectomy versus breast conservation therapy. Cancer. 2003;98(4):697-702. doi: $10.1002 /$ cncr. 11580

7. Breast cancer treatment (adult) $\left(\mathrm{PDQ}^{\circledR}\right)$-patient version; December 4 , 2021. Available from: https://www.cancer.gov/types/breast/patient/ breast-treatment-pdq. Accessed June 14, 2021.

8. Wheeler SB, Reeder-Hayes KE, Carey LA. Disparities in breast cancer treatment and outcomes: biological, social, and health system determinants and opportunities for research. Oncologist. 2013;18 (9):986-993. doi:10.1634/theoncologist.2013-0243

9. Hurd TC, James T, Foster JM. Factors that affect breast cancer treatment: underserved and minority populations. Surg Oncol Clin N Am. 2005;14(1):119-130, vii. doi:10.1016/j.soc.2004.08.001

10. McGuire TG, Alegria M, Cook BL, Wells KB, Zaslavsky AM. Implementing the institute of medicine definition of disparities: an application to mental health care. Health Serv Res. 2006;41 (5):1979-2005. doi:10.1111/j.1475-6773.2006.00583.x

11. Horwitz RI. Equity in cancer care and outcomes of treatment: a different type of cancer moonshot. JAMA. 2016;315 (12):1231-1232. doi:10.1001/jama.2016.2242

12. Bradley CJ, Given CW, Roberts C. Race, socioeconomic status, and breast cancer treatment and survival. $J$ Natl Cancer Inst. 2002;94 (7):490-496. doi:10.1093/jnci/94.7.490

13. Galobardes B, Shaw M, Lawlor DA, Lynch JW, Davey Smith G. Indicators of socioeconomic position (part 1). J Epidemiol Community Health. 2006;60(1):7-12. doi:10.1136/jech.2004.023531

14. Shinagawa SM. The excess burden of breast carcinoma in minority and medically underserved communities: application, research, and redressing institutional racism. Cancer. 2000;88(5 Suppl):1217-1223. doi:10.1002/(SICI)1097-0142(20000301)88:5+<1217::AIDCNCR7>3.0.CO;2-K

15. Polacek GNLJ, Ramos MC, Ferrer RL. Breast cancer disparities and decision-making among U.S. women. Patient Educ Couns. 2007;65 (2):158-165. doi:10.1016/j.pec.2006.06.003
16. Chapter 3: defining the criteria for including studies and how they will be grouped for the synthesis. Available from: https://training. cochrane.org/handbook/current/chapter-03. Accessed June 14, 2021.

17. Ouzzani M, Hammady H, Fedorowicz Z, Elmagarmid A. Rayyan-a web and mobile app for systematic reviews. Syst Rev. 2016;5(1):210. doi:10.1186/s13643-016-0384-4

18. Porzio G. Non clinical factors as determinants of the use of breast conservative surgery in Italy. Tumori. 2003;89(2):168-172. doi: $10.1177 / 030089160308900212$

19. Aziz Z, Iqbal J, Akram M, Anderson BO. Worsened oncologic outcomes for women of lower socio-economic status (SES) treated for locally advanced breast cancer (LABC) in Pakistan. Breast. 2010;19 (1):38-43. doi:10.1016/j.breast.2009.10.005

20. Chen R, You S, Yin Z, et al. Non-doctoral factors influencing the surgical choice of Chinese patients with breast cancer who were eligible for breast-conserving surgery. World J Surg Oncol. 2019;17 (1):189. doi:10.1186/s12957-019-1723-4

21. Dalton SO, Ross L, Düring M, et al. Influence of socioeconomic factors on survival after breast cancer-a nationwide cohort study of women diagnosed with breast cancer in Denmark 1983-1999. Int J Cancer. 2007;121(11):2524-2531. doi:10.1002/ijc.22979

22. Frisell A, Lagergren J, Halle M, de Boniface J. Socioeconomic status differs between breast cancer patients treated with mastectomy and breast conservation, and affects patient-reported preoperative information. Breast Cancer Res Treat. 2020;179(3):721-729. doi:10.1007/s10549-019-05496-2

23. Haybittle J, Houghton J, Baum M. Social class and weight as prognostic factors in early breast cancer. $B r J$ Cancer. 1997;75 (5):729-733. doi:10.1038/bjc.1997.129

24. Lautner M, Lin H, Shen Y, et al. Disparities in the use of breast-conserving therapy among patients with early-stage breast cancer. JAMA Surg. 2015;150(8):778-786. doi:10.1001/ jamasurg.2015.1102

25. Li J, Cornacchi SD, Farrokhyar F, et al. Relation between socioeconomic variables and surgical, systemic and radiation treatment in a cohort of patients with breast cancer in an urban Canadian centre. Can J Surg. 2019;62(2):83-92. doi:10.1503/cjs.009217

26. Liu -J-J, Zhang S, Hao X, et al. Breast-conserving therapy versus modified radical mastectomy: socioeconomic status determines who receives what-results from case-control study in Tianjin, China. Cancer Epidemiol. 2012;36(1):89-93. doi:10.1016/j.canep.20 11.04 .005

27. Riba LA, Gruner RA, Alapati A, James TA. Association between socioeconomic factors and outcomes in breast cancer. Breast $J$. 2019;25(3):488-492. doi:10.1111/tbj.13250

28. Wright GP, Wong JH, Morgan JW, Roy-Chowdhury S, Kazanjian K, Lum SS. Time from diagnosis to surgical treatment of breast cancer: factors influencing delays in initiating treatment. Am Surg. 2010;76 (10):1119-1122. doi:10.1177/000313481007601022

29. Zhang L, Jiang M, Zhou Y, et al. Survey on breast cancer patients in China toward breast-conserving surgery. Psychooncology. 2012;21 (5):488-495. doi:10.1002/pon.1922

30. Lyle G, Hendrie GA, Hendrie D. Understanding the effects of socioeconomic status along the breast cancer continuum in Australian women: a systematic review of evidence. Int $J$ Equity Health. 2017;16(1):182. doi:10.1186/s12939-017-0676-x

31. Mac Bride MBM, Neal L, Dilaveri CA, et al. Factors associated with surgical decision making in women with early-stage breast cancer: a literature review. $J$ Womens Health. 2013;22(3):236-242. doi: $10.1089 /$ jwh.2012.3969

32. Scalia P, Durand M-A, Berkowitz JL, et al. The impact and utility of encounter patient decision aids: systematic review, meta-analysis and narrative synthesis. Patient Educ Couns. 2019;102(5):817-841. doi:10.1016/j.pec.2018.12.020 
33. Durand M-A, Yen RW, O'Malley AJ, et al. What matters most: randomized controlled trial of breast cancer surgery conversation aids across socioeconomic strata. Cancer. 2020. doi:10.1002/ cncr.33248
34. Berkowitz SA, Traore CY, Singer DE, Atlas SJ. Evaluating area-based socioeconomic status indicators for monitoring disparities within health care systems: results from a primary care network. Health Serv Res. 2015;50(2):398-417. doi:10.1111/1475-6773.12229

\section{Publish your work in this journal}

Breast Cancer - Targets and Therapy is an international, peer-reviewed open access journal focusing on breast cancer research, identification of therapeutic targets and the optimal use of preventative and integrated treatment interventions to achieve improved outcomes, enhanced survival and quality of life for the cancer patient.
The manuscript management system is completely online and includes a very quick and fair peer-review system, which is all easy to use. Visit http://www.dovepress.com/testimonials.php to read real quotes from published authors. 